\title{
Trends in road injury hospitalisation rates for Aboriginal and non-Aboriginal people in Western Australia, 1971-97
}

\author{
L R Cercarelli, M W Knuiman
}

Injury Prevention 2002;8:211-215

See end of article for authors' affiliations

.....................

Correspondence to: Dr Rina Cercarelli, Injury Research Centre, Department of Public Health, University of Western Australia, 35 Stirling Hwy, Crawley, WA 6009, Australia; rina@dph.uwa.edu.au

\begin{abstract}
Objective: To examine trends in road injury hospitalisation rates for Aboriginal and non-Aboriginal people in Western Australia.

Methods: Data from the Western Australian Hospital Morbidity Data System for the years between 1971 and 1997 were analysed. Poisson regression models were fitted to determine whether the trends were significant.

Results: The rate of hospitalisation due to road injury for Aboriginal people 1719.1 per 100000 population per year) over the time period examined was almost twice as high as that for non-Aboriginal people (363.4 per 100000 population per year). Overall, the results showed that while hospitalisations from road injury involving non-Aboriginal people have been decreasing by $6.7 \%$ per three year period since 1971, the rates of hospitalisation for Aboriginal people have been increasing by $2.6 \%$ per three year period. Both of these trends were statistically significant. The alarming increasing trend observed for Aboriginal people was more pronounced in males, those aged 0-14 years and over 45 years, and for those living in rural areas.

Conclusions: As the rates of road injury for Aboriginal people are higher than for non-Aboriginal people, and are also following an increasing trend, road safety issues involving Aboriginal people need to be addressed urgently by health and transport authorities.
\end{abstract}

$\mathrm{R}$ oad injury is a major public health problem and is particularly the case for road injuries involving Aboriginal people in Western Australia who have much higher rates of road injury when compared with non-Aboriginal people. ${ }^{1-3}$

Despite an increasing population, increasing vehicle ownership, and increasing travel in Australia, the total number of road injuries has decreased over time since the 1970s. This decrease has been attributed to a combination of factors including the application of Australian design rules such as the mandatory fitting of seat belts in new passenger vehicles, the use of head restraints, and increased vehicle impact resistance. ${ }^{4}$ Random breath testing programs in Australia are now some of the most intensive for the mass breath testing of drivers in the world. ${ }^{4}$ Maximum legal blood alcohol levels for drivers were also reduced to $0.05 \%$ during this time period. Other factors such as improved roads and improved police enforcement strategies have also contributed to the decreasing trend in road injuries in Australia. ${ }^{4}$

While the trend for road injuries in the total population has been decreasing in Western Australia since the 1970s, it is not clear whether this same pattern is also evident for Aboriginal people. The aim of this study was to examine hospital admission data in Western Australia (where Aboriginal and non-Aboriginal people are identified) to compare the trends in road injuries. Other than death data from the Registrar General (where the numbers are small for Western Australia), hospital data are the only data available where Aboriginality is recorded, along with cause of injury or hospitalisation.

\section{DATA SOURCES AND METHODS}

\section{Western Australian Hospital Morbidity Data System}

The Western Australian Hospital Morbidity Data System, which is maintained by the Department of Health in Western Australia, has information for all hospitalisations in Western
Australia for both public and private hospitals from 1971. The period examined in this study was 1971-97.

The E codes (or external causes) included in these analyses from which it is possible to determine the cause and type of injury were 810.0-829.9 and 929.0. For the years before 1988, the E codes were those based on the equivalent International Classification of Diseases, ninth revision, clinical modification (ICD9-CM) classifications. ${ }^{5}$ This was the first year that the Department of Health introduced ICD9-CM. The E codes included motor vehicle traffic accidents (810.0-819.9), motor vehicle non-traffic accidents (820.0-825.9), and other road vehicle accidents (826.0-829.9). These E codes include the broadest definition of a road injury so that road injury hospitalisations that are likely to involve Aboriginal people (such as those occurring in remote areas, or motor vehicle non-traffic accidents) that are often missed in police crash reports were included.

Information that is recorded and that is relevant to the following analyses are year of admission, race (Aboriginal or non-Aboriginal), age, gender, area of residence (not area of crash), and road user type. The Hospital Morbidity Data System, however, contains no details on the characteristics of the crash.

\section{Population data and rates}

The denominators used were population data. These were the only denominator data available as there were no estimates of road travel or vehicle ownership for Aboriginal people in Western Australia.

The population data used to calculate rates for nonAboriginal people were obtained from Australian Bureau of

Abbreviations: $\mathrm{Cl}$, confidence interval; ICD9-CM, International Classification of Diseases, ninth revision, clinical modification 


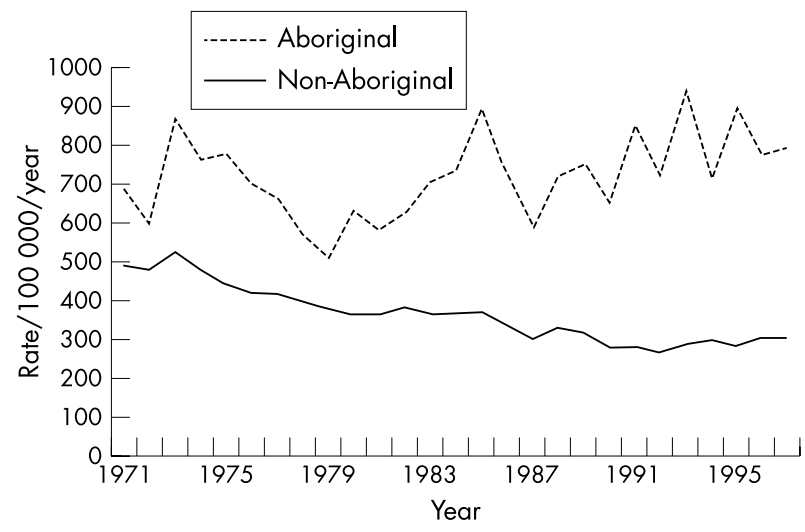

Figure 1 Trends in road injury hospitalisation rates in Western Australia for Aboriginal and non-Aboriginal people, 1971-97.

Statistics publications on the estimated resident population by sex and age. ${ }^{6}$

The population of Aboriginal people in Western Australia was estimated by the Australian Bureau of Statistics from 1971 to 1992 as a special request from the Road Accident Prevention Research Unit (now the Injury Research Centre). Before 1971, Aboriginal people were not counted separately by the Australian Bureau of Statistics. Estimations were made by either gender, age group, or for the metropolitan and rural areas. Estimates by a combination of these variables were not possible. Aboriginal population estimates for the period 1993-97 were obtained from Australian Bureau of Statistics publications. ${ }^{7}$

Poisson regression models were fitted to determine whether the trends were significant. For these models, year was grouped into three year periods starting 1971-73, 1974-76, etc. The terms in each of the models were year, race, and the interaction of year and race. Models were fitted comparing Aboriginal and non-Aboriginal people for each gender separately (males and females), age group separately (0-14 years, 15-24, 25-44, 45-64, and 65 plus), and area of residence separately (metropolitan and rural). Only one of gender, age group or area of residence could be examined at a time as population data were not available for Aboriginal people under a combination of these variables.

\section{RESULTS}

\section{Trends}

Between 1971 and 1997, non-Aboriginal people comprised $94.6 \%$ of road injury hospitalisations (ranging from $96.8 \%$ in 1972 to $91.5 \%$ in 1993) and Aboriginal people comprised 5.4\% (ranging from $3.2 \%$ in 1972 to $8.5 \%$ in 1993).

Figure 1 shows the trends in road injury hospitalisation rates in Western Australia for Aboriginal and non-Aboriginal people between 1971 and 1997. Over the period examined, Aboriginal people had a higher rate of hospitalisation resulting from a road injury than non-Aboriginal people. The mean rate of hospitalisation for Aboriginal people during this time period was 719.1 per 100000 population per year, compared with 363.4 per 100000 population per year for nonAboriginal people.

Poisson regression modelling showed that the trends over time were significantly different for Aboriginal and nonAboriginal people $(\mathrm{p}<0.001)$. For Aboriginal people, there was an overall increasing trend with the rate increasing by approximately $2.6 \%$ per three year period (95\% confidence interval (CI) $1.7 \%$ to $3.5 \%$ ). For non-Aboriginal people, there was an overall decreasing trend with the rate decreasing by approximately $6.7 \%$ per three year period (95\% CI $6.5 \%$ to $6.9 \%)$. The rates for Aboriginal people show more variability from year to year due to the small numbers.

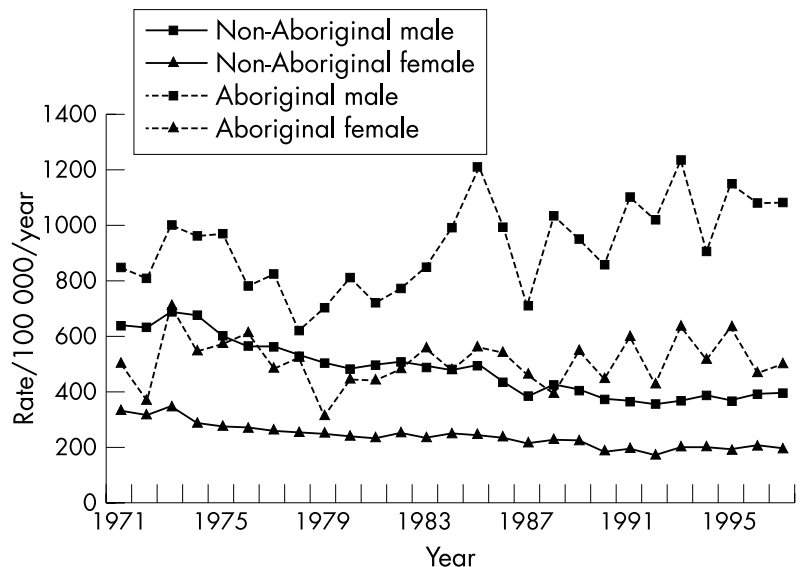

Figure 2 Trends in road injury hospitalisation rates in Western Australia for Aboriginal and non-Aboriginal people by gender, 1971-97.

Figure 2 shows the trends in hospitalisation rates for Aboriginal and non-Aboriginal people by gender. The rates of hospitalisation were higher for Aboriginal males compared with non-Aboriginal males, and higher for Aboriginal females compared with non-Aboriginal females. Non-Aboriginal females had the lowest rates of hospitalisation and Aboriginal males had the highest rates of hospitalisation.

Poisson regression modelling showed that the trends over time were significantly different for Aboriginal and nonAboriginal males $(p<0.001)$, and Aboriginal and nonAboriginal females $(p<0.001)$. For Aboriginal males, there was an overall increasing trend with the rate increasing by approximately $3.9 \%$ per three year period (95\% CI $2.7 \%$ to $5.0 \%)$. For non-Aboriginal males, there was an overall decreasing trend with the rate decreasing by approximately $7.0 \%$ per three year period ( $95 \%$ CI $6.8 \%$ to $7.3 \%$ ).

For Aboriginal females, there was no significant trend over time $(p=0.44)$. For non-Aboriginal females, there was an overall decreasing trend with the rate decreasing by approximately $5.8 \%$ per three year period ( $95 \%$ CI $5.4 \%$ to $6.1 \%$ ).

Figure 3 shows trends in road injury hospitalisation rates by age group for Aboriginal and non-Aboriginal people. The age groups were selected on the basis of available population estimates for Aboriginal people.

The rates of hospitalisation were generally higher for Aboriginal people of every age group compared with non-Aboriginal people. Generally, the rates of hospitalisation were highest for Aboriginal people aged 15-24 years and 25-44 years.

Poisson regression modelling showed that the trends over time were significantly different for Aboriginal and nonAboriginal people aged $0-14$ years $(\mathrm{p}<0.001)$, Aboriginal and non-Aboriginal people aged $15-24(\mathrm{p}<0.001)$, Aboriginal and non-Aboriginal people aged $25-44(\mathrm{p}<0.001)$, Aboriginal and non-Aboriginal people aged 45-64 $(\mathrm{p}<0.001)$, and Aboriginal and non-Aboriginal people aged 65 years and over $(p=0.005)$.

For Aboriginal people aged 0-14 years, there was an overall increasing trend with the rate increasing by approximately $8.1 \%$ per three year period (95\% CI $6.2 \%$ to $10.1 \%$ ). For non-Aboriginal people aged $0-14$, there was an overall decreasing trend with the rate decreasing by approximately $3.2 \%$ per three year period ( $95 \%$ CI $2.7 \%$ to $3.7 \%$ ).

For Aboriginal people aged 15-24 years, there was an overall decreasing trend with the rate decreasing by approximately $3.0 \%$ per three year period ( $95 \%$ CI $1.4 \%$ to $4.5 \%$ ). This was the only statistically significant decreasing trend identified for Aboriginal people. For non-Aboriginal people aged 15-24, there was also an overall decreasing trend with the rate decreasing by approximately $8.2 \%$ per three year period $(95 \%$ CI $7.9 \%$ to $8.5 \%$ ). 

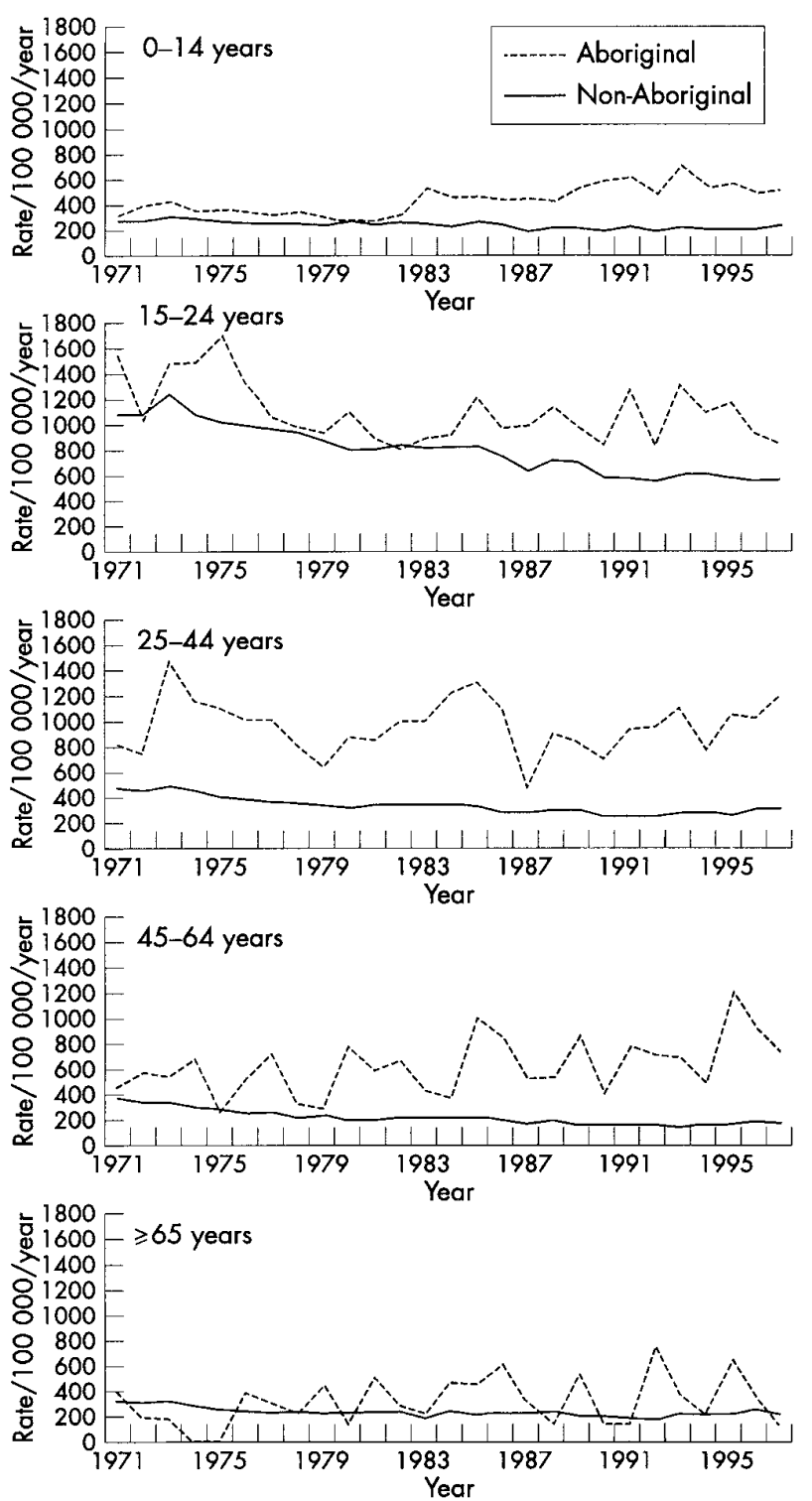

Figure 3 Trends in road injury hospitalisation rates in Western Australia for Aboriginal and non-Aboriginal people by age group, 1971-97.

There was no significant trend $(p=0.64)$ for Aboriginal people aged 25-44 years. For non-Aboriginal people aged 25 to 44 , there was an overall decreasing trend with the rate decreasing by approximately $5.5 \%$ per three year period $(95 \%$ CI $5.2 \%$ to $5.9 \%$ ).

For Aboriginal people aged 45-64 years, there was an overall increasing trend with the rate increasing by approximately $7.8 \%$ per three year period (95\% CI $4.5 \%$ to $11.1 \%$ ). For non-Aboriginal people aged 45-64, there was an overall decreasing trend with the rate decreasing by approximately $7.4 \%$ per three year period (95\% CI 6.9\% to $8.0 \%$ ).

For Aboriginal people aged 65 years and over, there was an overall increasing trend with the rate increasing by approximately $8.4 \%$ per three year period (95\% CI $0.6 \%$ to $16.7 \%$ ). For non-Aboriginal people aged 65 years and over, there was an overall decreasing trend with the rate decreasing by approximately $2.6 \%$ per three year period ( $95 \%$ CI $1.7 \%$ to $3.4 \%$ ).

Figure 4 presents the rates of hospitalisation from road injury for Aboriginal and non-Aboriginal people by area of residence. The rates of hospitalisation were higher for Aboriginal people in the metropolitan area compared with

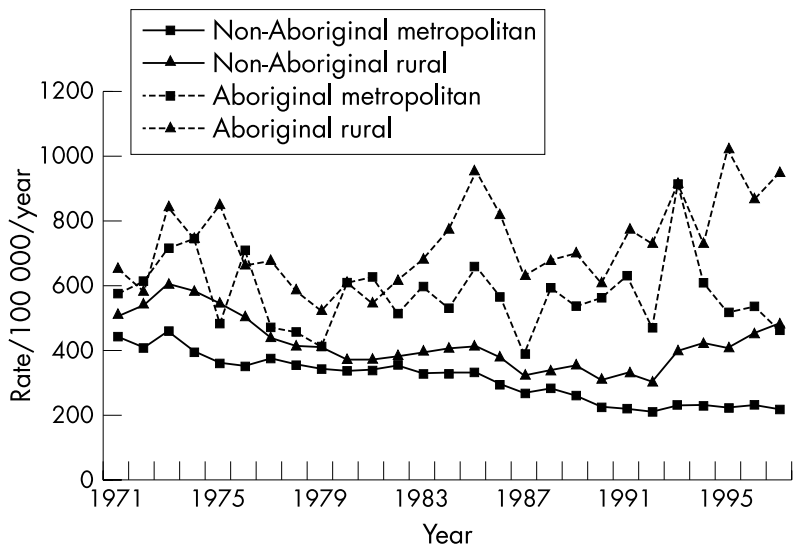

Figure 4 Trends in road injury hospitalisation rates in Western Australia for Aboriginal and non-Aboriginal people by area of residence, 1971-97.

non-Aboriginal people in the metropolitan area, and higher for Aboriginal people in the rural area compared with non-Aboriginal people in the rural area.

The lowest rate of hospitalisation was for non-Aboriginal people in the metropolitan area. This was followed by the rate of hospitalisation for non-Aboriginal people in the rural area. The highest rate of hospitalisation was for rural Aboriginal people.

Poisson regression modelling showed that the trends over time were significantly different for Aboriginal and nonAboriginal people in the metropolitan area $(p<0.001)$, and Aboriginal and non-Aboriginal people in the rural area $(p<0.001)$. For Aboriginal people in the metropolitan area, there was no significant trend $(p=0.46)$. For non-Aboriginal people in the metropolitan area, there was an overall decreasing trend with the rate decreasing by approximately $8.3 \%$ per three year period (95\% CI $8.0 \%$ to $8.5 \%$ ).

For Aboriginal people in the rural area, there was an overall increasing trend with the rate increasing by approximately $3.8 \%$ per three year period (95\% CI $2.8 \%$ to $4.9 \%$ ). For non-Aboriginal people in the rural area, there was an overall decreasing trend with the rate decreasing by approximately $3.9 \%$ per three year period ( $95 \%$ CI $3.5 \%$ to $4.2 \%$ ).

\section{Road user type}

Road user type can be determined from the fourth digit of the E code. Overall, non-Aboriginal people had a higher proportion of people hospitalised who were drivers $(20.9 \%$ compared with $9.8 \%$ of Aboriginal people hospitalised), motorcyclists $(15.6 \%$ compared with $5.5 \%$ of Aboriginal people hospitalised), and cyclists (10.8\% compared with $6.6 \%$ of Aboriginal people hospitalised).

Aboriginal people had a higher proportion of passengers hospitalised compared with non-Aboriginal people $(22.9 \%$ compared with $15.6 \%$ ), and a much higher proportion of pedestrians who were hospitalised $(16.3 \%$ compared with $7.7 \%$ of non-Aboriginal people hospitalised).

\section{DISCUSSION}

Aboriginal people made up 5.4\% of hospitalisations in Western Australia between 1971 and 1997, while non-Aboriginal people made up $94.6 \%$ of hospitalisations. The rate of hospitalisation due to road injury for Aboriginal people (719.1 per 100000 population per year) over the time period examined was almost twice as high as that for non-Aboriginal people (363.4 per 100000 population per year). Overall, the results showed that while hospitalisations from road injury involving non-Aboriginal people have been decreasing by $6.7 \%$ per three year period since 1971, the rates of hospitalisation 
for Aboriginal people have been increasing by $2.6 \%$ per three year period. Both of these trends were statistically significant.

There were also differences in rates of hospitalisation by gender, age group, and area of residence between Aboriginal and non-Aboriginal people. Hospitalisation rates involving Aboriginal males were consistently higher than any other group. While hospitalisations involving non-Aboriginal males and females decreased by $7.0 \%$ and $5.8 \%$ respectively per three year period since 1971, hospitalisations involving Aboriginal males increased by $3.9 \%$ per three year period.

Rates of hospitalisation from road injury were highest for Aboriginal people for every age group examined. The highest rates were in the 15-24 year age group for both Aboriginal and non-Aboriginal people. While the rates in every age group for non-Aboriginal people have been decreasing significantly between $2.6 \%$ and $8.2 \%$ per three year period, the rates for Aboriginal people showed different trends. The trends for Aboriginal people aged $0-14,45-64$, and 65 years and over have been increasing significantly from between $7.8 \%$ and $8.4 \%$ per three year period. However, the trend has been decreasing significantly by $3.0 \%$ per three year period for Aboriginal people aged 15-24 years. From these data, it is difficult to determine the reasons for this decrease.

When examining the area of residence of those hospitalised because of a road injury, the highest rate of hospitalisation was found for Aboriginal people living in rural areas. This was increasing by $3.8 \%$ per three year period. While the rate for Aboriginal people in the metropolitan area was also high, there was no statistical change in the trend over time.

The majority of Aboriginal people hospitalised were either passengers in vehicles or pedestrians. The majority of non-Aboriginal people hospitalised were drivers, passengers, or motorcyclists.

The overall decrease in road injury hospitalisation rates involving non-Aboriginal people identified in this study mirrors national and international research on trends in road injuries. ${ }^{48}$ Many initiatives have occurred that would explain this overall decrease. These include safer vehicles with design improvements, safer roads, and safer road users with the implementation of maximum blood alcohol limits, helmet wearing, and many other initiatives. ${ }^{9}$

Despite these road safety countermeasures, rates of road injury hospitalisation have been increasing for Aboriginal people. There are several explanations that could be relevant for the increasing trend in road injury hospitalisation rates involving Aboriginal people in Western Australia. Firstly, an increasing trend for Aboriginal people may be due to an actual greater involvement in road crashes. This is possible due to the increasing availability and accessibility of vehicles and therefore increased exposure to road injury. Improved access to roads in rural and remote areas may have also contributed to this.

Many of the road safety initiatives that have been introduced in Western Australia may not have been relevant to Aboriginal people. The inadequacies of both roads and vehicles used by Aboriginal people in rural and remote areas has also been noted. ${ }^{10}$ Furthermore, the vehicles used by Aboriginal people in rural and remote areas are not appropriate for the conditions for which they are used. ${ }^{10}$ Many of these vehicles are also older and therefore do not have the benefits of improved safety features. It has also been noted that there is limited funding available for access roads. ${ }^{10}$ The poor condition of such roads substantially contributes to vehicle deterioration and breakdown. An example of an intervention that has been considered successful in road safety is random breath testing. ${ }^{11}$ However, due to limited resources, random breath testing has not been conducted with the same intensity in rural and remote areas as in the metropolitan area of Western Australia.

The increase in hospitalisations involving Aboriginal people may also be due to growing acceptance over time of being
"Aboriginal". The changing propensity to identify as Aboriginal is also recognised by the Australian Bureau of Statistics. This changing propensity could vary over time and between regions. The Australian Bureau of Statistics conducts a post enumeration survey three weeks after the census asking selected questions including one on indigenous origin. After the 1991 census there was about a $1 \%$ change in response to this question.

This issue has also been identified elsewhere. For example, $6 \%$ of people who identified as Negro in 1971 or 1972 placed themselves in another category 12 months later. ${ }^{12}$ As noted by the Australian Bureau of Statistics, given the lack of data, it is difficult to quantify any changes over time in the propensity to identify as being of Aboriginal origin. ${ }^{7}$ This, in combination with improved coding practices by hospitals and the Health Department of Western Australia, may mean that hospital data may now more accurately reflect Aboriginality.

Improved access to hospitals for Aboriginal people over time, particularly for those residing in rural and remote areas, may also account for the significant increase in hospitalisation rates in the rural area for Aboriginal people. Medical services in Kimberley in Western Australia were aimed initially at addressing the needs of the European (non-Aboriginal) population. ${ }^{13}$ Many Aboriginal people remained mobile and scattered in small groups, which made health care functionally unavailable for Aboriginal people until comparatively recently. Over time, Aboriginal people may have also become more ready to accept and trust hospital services.

While the data are complete for Western Australia, comment should be made on some potential problems with this hospital data source. The main problem would be related to the miscoding of "race". The default in the coding system has always been to code a person as being non-Aboriginal if the person collecting the information was uncertain as to the person's race. This would lead to an underestimate of the number of Aboriginal people hospitalised in Western Australia according to the hospital data. It is therefore likely that the figures reported in this study are an underestimate of the number of Aboriginal people hospitalised as a result of a road injury.

Another potential problem with the analyses in this study is with the population figures. Aboriginal people were not counted in any census in Australia until 1971. ${ }^{13}$ Without the Aboriginal population estimates provided by the Australian Bureau of Statistics, it would not have been possible to determine rates of hospitalisations from road injury. The two recurring problem areas in the analysis of Aboriginal data are the definition of the denominator (that is, the Aboriginal population) and in the numerator. ${ }^{13}$

As it is very likely that patterns of vehicle ownership and road travel have changed over the last 20 to 30 years, including for Aboriginal people, it is important that mortality rates and rates of hospitalisation from road injury are examined taking into account vehicle ownership and kilometres travelled. However, while these exposure measures are available for the total population and are commonly used, they are unavailable for Aboriginal people.

\section{IMPLICATIONS FOR PREVENTION}

The findings from this analysis have implications for the prevention of road injuries involving Aboriginal people. Not only were the rates of hospitalisation for Aboriginal people higher than for non-Aboriginal people, the rates were generally also increasing over time. While hospitalisation rates from road injury were increasing for almost every Aboriginal group examined, the rates for Aboriginal people aged 15-24 years, however, were actually decreasing significantly. It would be important to be able to identify the reasons for the decrease in road injuries for this age group so that they might then be applied to other age groups, if appropriate. It may be that some 


\section{Key points}

- The rate of hospitalisation due to road injury for Aboriginal people over the time period examined was almost twice as high as that for non-Aboriginal people.

- Overall, the results showed that while hospitalisations from road injury involving non-Aboriginal people have been decreasing since 1971, the rates of hospitalisation for Aboriginal people have been increasing.

- The alarming increasing trend observed for Aboriginal people was more pronounced in males, those aged 0-14 years and over 45 years, and for those living in rural areas.

- The rate of hospitalisation was also high for Aboriginal people living in the metropolitan area.

- Countermeasures also need to be directed to reducing the impact of pedestrian injuries and those involving passengers.

- As the rates of road injury for Aboriginal people are higher than for non-Aboriginal people, and are following an increasing trend, road safety issues involving Aboriginal people need to be addressed urgently by health and transport authorities.

of the effective countermeasures that have been targeted to the non-Aboriginal population may also be relevant to this group of Aboriginal people.

The analyses in this study have also highlighted high rates of road injury for Aboriginal people in the metropolitan area. This is another area where road safety interventions could be directed.

The rates of road injury for Aboriginal people are higher than for non-Aboriginal people in Western Australia, and are also following an increasing trend. Road safety issues involving Aboriginal people therefore need to be addressed urgently by health and transport authorities. Countermeasures also need to be directed to reducing the impact of pedestrian injuries and those involving passengers.

\section{ACKNOWLEDGEMENTS}

The authors would like to thank Dr G Anthony Ryan for comments on an earlier version of this paper, and Ms Diana Rosman who assisted with the extraction of the data.

\section{Authors' affiliations}

L R Cercarelli, Injury Research Centre, Department of Public Health, University of Western Australia

M W Knuiman, Department of Public Health, University of Western Australia

\section{REFERENCES}

1 Cercarelli LR. Road crashes involving Aboriginal people in Western Australia. Accid Anal Prev 1994:26:361-9.

2 Cercarelli LR. Road crash hospitalisations and deaths in Western Australia involving Aboriginal and non-Aboriginal people, 1988 to 1996. Perth: Road Accident Prevention Research Unit, RR87, 1999.

3 Cercarelli LR, Ryan GA, Knuiman MK, et al. Road safety issues in remote Aboriginal communities in Western Australia. Accid Anal Prev 2000;32:845-8.

4 Federal Office of Road Safety. The history of road fatalities in Australia. Canberra: Federal Office of Road Safety, Monograph 23 1998.

5 International classification of diseases revision 9-clinical modification (ICD9 CM). Ann Arbor, Michigan: Edwards Brothers Inc, 1986.

6 Australian Bureau of Statistics. Estimated resident population by sex and age: states and territories of Australia. Canberra: Australian Bureau of Statistics, various catalogue numbers; various years.

7 Australian Bureau of Statistics. Experimental projections: Aboriginal and Torres Strait Islander population. Canberra: Australian Bureau of Statistics, catalogue number 3231.0, 1996

8 Federal Office of Road Safety. Australia's international road safety performance 1996. Canberra: Federal Office of Road Safety, Monograph 28, 1999

9 Evans L. Traffic safety and the driver. New York: Van Nostrand Reinhold, 1991

10 Alexander P. Safety, in emergency situations, for Aboriginal people located in remote areas of Western Australia. Perth: Aboriginal Affairs Planning Authority, 1990.

11 Sheehan M. Alcohol controls and drink driving: the social context. Canberra: Federal Office of Road Safety, CR 142, 1994

12 Farley $\mathbf{R}$. The new census questions about ancestry: what did it tell us? Demography 1991;28:411-29.

13 Hunter E. Aboriginal health and history: power and prejudice in remote Australia. Melbourne: Cambridge University Press, 1993

If you wish to comment on any article published in Injury Prevention you can send an eLetter using the eLetters link at the beginning of each article. Your response will be posted on

Injury Prevention online within a few days of receipt (subject to editorial screening). 